\title{
Chromogranin A as Serum Marker for Neuroendocrine Neoplasia: Comparison with Neuron-Specific Enolase and the $\alpha$-Subunit of Glycoprotein Hormones
}

\author{
FRANK R. E. NOBELS, DIK J. KWEKKEBOOM, WILLY COOPMANS, \\ CHRISTIAAN H. H. SCHOENMAKERS, JAN LINDEMANS, \\ WOUTER W. DE HERDER, ERIC P. KRENNING, ROGER BOUILLON, AND \\ STEVEN W. J. LAMBERTS
}

\author{
Departments of Medicine (F.N., W.D.H., S.L.), Nuclear Medicine (D.K., E.K.), and Clinical Laboratory \\ (C.S., J.L.), University Hospital Dijkzigt, Rotterdam, The Netherlands; and the Laboratory of \\ Experimental Medicine and Endocrinology, University Hospital Gasthuisberg (W.C., R.B.), \\ Leuven, Belgium
}

\begin{abstract}
Chromogranin $\mathrm{A}(\mathrm{CgA})$ is gaining acceptance as a serum marker of neuroendocrine tumors. Its specificity in differentiating between neuroendocrine and nonneuroendocrine tumors, its sensitivity to detect small tumors, and its clinical value, compared with other neuroendocrine markers, have not clearly been defined, however. The objectives of this study were to evaluate the clinical usefulness of $\mathrm{CgA}$ as neuroendocrine serum marker. Serum levels of $\mathrm{CgA}$, neuron-specific enolase (NSE), and the $\alpha$-subunit of glycoprotein hormones ( $\alpha$ $\mathrm{SU}$ ) were determined in 211 patients with neuroendocrine tumors and 180 control subjects with nonendocrine tumors. The concentrations of $\mathrm{CgA}, \mathrm{NSE}$, and $\alpha$-SU were elevated in $50 \%, 43 \%$, and $24 \%$ of patients with neuroendocrine tumors, respectively. Serum CgA was most frequently increased in subjects with gastrinomas (100\%), pheochromocytomas $(89 \%)$, carcinoid tumors $(80 \%)$, nonfunctioning tumors of the endocrine pancreas $(69 \%)$, and medullary thyroid carcinomas $(50 \%)$. The highest levels were observed in subjects with carcinoid tumors. NSE was most frequently elevated in patients with small cell lung carcinoma (74\%), and $\alpha$-SU was most frequently elevated in patients
\end{abstract}

with carcinoid tumors (39\%). Most subjects with elevated $\alpha$-SU levels also had elevated $\mathrm{CgA}$ concentrations. A significant positive relationship was demonstrated between the tumor load and serum CgA levels $\left(P<0.01\right.$, by $\chi^{2}$ test). Elevated concentrations of CgA, NSE, and $\alpha$-SU were present in, respectively, $7 \%, 35 \%$, and $15 \%$ of control subjects. Markedly elevated serum levels of CgA, exceeding $300 \mu \mathrm{g} / \mathrm{L}$, were observed in only $2 \%$ of control patients $(n=3)$ compared to $40 \%$ of patients with neuroendocrine tumors $(\mathrm{n}=76)$. We conclude that $\mathrm{CgA}$ is the best general neuroendocrine serum marker available. It has the highest specificity for the detection of neuroendocrine tumors compared to the other neuroendocrine markers, NSE and $\alpha$-SU. Elevated levels are strongly correlated with tumor volume; therefore, small tumors may go undetected. Although its specificity cannot compete with that of the specific hormonal secretion products of most neuroendocrine tumors, it can have useful clinical applications in subjects with neuroendocrine tumors for whom either no marker is available or the marker is inconvenient for routine clinical use. (J Clin Endocrinol Metab 82: 2622-2628, 1997)
HROMOGRANIN A $(\mathrm{CgA})$ is a protein that is present in the secretory dense core granules of neuroendocrine tissues (1). It is widely used as an immunohistochemical marker of neuroendocrine tumors. It can also serve as a serum marker, as it is cosecreted with the amines and peptides that are present in the neurosecretory granules (2). It is at present considered to be a very sensitive and specific serum marker of neuroendocrine tumors. The concentrations often remain increased in cases of less well differentiated tumors of neuroendocrine origin that do not secrete known hormones (3). The publications on $\mathrm{CgA}$ as a serum marker of neuroendocrine neoplasia deal with rather small numbers of patients and small numbers of control subjects with nonneuroendocrine neoplasms $(2,4,5)$. Most neuroendocrine tumors included are far advanced, with a large tumor volume. Data on the specificity of $\mathrm{CgA}$ for the differentiation between neuroendocrine and nonneuroendocrine tumors

Received September 18, 1996. Revision received April 23, 1997. Accepted May 2, 1997.

Address all correspondence and requests for reprints to: Dr. F. Nobels, Department of Endocrinology, Onze Lieve Vrouw Hospital, 164 Moorselbaan, 9300 Aalst, Belgium. and on its sensitivity for the detection of small neuroendocrine tumors are sparse or lacking. There are also no large studies available in which $\mathrm{CgA}$ is compared with other neuroendocrine markers, such as neuron-specific enolase (NSE) and the $\alpha$-subunit of glycoprotein hormones ( $\alpha$-SU).

We investigated the roles of the serum concentrations of $\mathrm{CgA}, \mathrm{NSE}$, and $\alpha$-SU in a large study group of patients with neuroendocrine tumors, including tumors with a small volume, and in a control group consisting of patients with several nonendocrine tumors. The results suggest that the determination of $\mathrm{CgA}$ is useful in selected clinical conditions when either no known specific peptide markers are available or when the available markers are inconvenient for routine clinical practice.

\section{Subjects and Methods}

\section{Patients}

Serum samples were obtained from 211 subjects with the following neuroendocrine neoplasms: carcinoid tumor $(n=62)$, medullary thyroid carcinoma $(\mathrm{n}=26)$, paraganglioma $(\mathrm{n}=25)$, pheochromocytoma $(\mathrm{n}=$ 9), neuroblastoma $(n=3)$, small cell lung carcinoma $(n=23)$, insulinoma $(n=21)$, gastrinoma $(n=9)$, nonfunctioning pancreatic islet cell tumor 
$(\mathrm{n}=13)$, Merkel cell tumor $(\mathrm{n}=4)$, clinically nonfunctioning pituitary adenoma $(n=10)$, and GH-secreting pituitary adenoma $(n=6)$. All diagnoses were made histologically, except in a few patients with small tumors of the neuroendocrine pancreas. In these cases the following diagnostic criteria were used: paradoxical rise in gastrin levels after stimulation by iv injection of secretin in gastrinoma, and hypoglycemia with inappropriate hypersecretion of insulin and $C$ peptide during a diagnostic fast in insulinoma. All plasma samples were obtained before operation.

Serum samples were also obtained from 180 subjects with a variety of "control" neoplasms of nonendocrine origin, both benign and malignant, including hematological and neurological tumors. This control group consisted of patients with breast carcinoma $(n=64)$, nonsmall cell lung cancer $(n=24)$, pancreatic adenocarcinoma $(n=21)$, adenocarcinoma of unknown origin $(n=12)$, non-Hodgkin lymphoma $(n=25)$, Hodgkin lymphoma $(n=13)$, multiple myeloma $(n=7)$, meningioma $(n=10)$, and astrocytoma $(n=4)$. All of these diagnoses were confirmed by histological examination.

\section{Immunoassays}

$\mathrm{CgA}$ was measured in serum samples, stored at $-20 \mathrm{C}$, by a polyclonal RIA, using human CgA isolated from pheochromocytomas as tracer and standard, as previously described (6). The within-assay coefficients of variation were $6.5 \%$ and $8.6 \%$ for mean concentrations of 95 and $1160 \mathrm{ng} / \mathrm{mL}(\mathrm{n}=18)$, respectively. The between-assay coefficients of variation were $6.9 \%$ and $6.3 \%$ for mean concentrations of 90 and 698 $\mathrm{ng} / \mathrm{mL}(\mathrm{n}=38)$, respectively. The detection sensitivity was $1.6 \mu \mathrm{g} / \mathrm{L}$. The CgA immunoreactivity remained stable whether the serum samples were immediately frozen or kept at $4 \mathrm{C}$ or at room temperature for $24 \mathrm{~h}$, or whether blood was centrifuged immediately to obtain serum or after 24-h storage at room temperature. The reference value in 568 normal subjects of both sexes, aged 6-50 yr, is $90 \pm 24 \mu \mathrm{g} / \mathrm{L}$ (range, 35-176); in 33 normal men older than $50 \mathrm{yr}$, it is $106 \pm 22 \mu \mathrm{g} / \mathrm{L}$ (range, 70-159); in 249 normal postmenopausal women older than $50 \mathrm{yr}$, it is $110.1 \pm 35.5$ $\mu \mathrm{g} / \mathrm{L}$ (range, 54-220). In men and premenopausal women, $175 \mu \mathrm{g} / \mathrm{L}$ was chosen as the upper cut-off value, and in postmenopausal women, $220 \mu \mathrm{g} / \mathrm{L}$ was used, to avoid overlapping values with normal subjects. This corresponds to slightly more than $3 \mathrm{SD}$ above the mean.

NSE was measured by RIA. The upper cut-off value is $12.5 \mu \mathrm{g} / \mathrm{L}$.

$\alpha$-Subunit was measured by RIA using antibodies purchased from UCB (Brussels, Belgium). The upper cut-off values are $1.1 \mu \mathrm{g} / \mathrm{L}$ in men, $2.3 \mu \mathrm{g} / \mathrm{L}$ in premenopausal women, and $4.0 \mu \mathrm{g} / \mathrm{L}$ in postmenopausal women.

\section{Determination of tumor mass}

The number of neuroendocrine tumor localizations was counted using computed tomography scan images and [111 In-DTPA-DPhe $^{1}$ loctreotide scanning (7). The tumor load was considered limited when one or two localizations were found; it was considered extensive when more than three localizations were demonstrated.

\section{Statistical analysis}

Results are reported as the mean \pm SD. To compare the different markers, $\chi^{2}$ tests and Spearman rank correlations were used. To study the effect of tumor load on circulating concentrations of the markers, $\chi^{2}$ tests were used.

\section{Results}

Serum concentrations of the markers $\mathrm{CgA}, \alpha$-SU, and NSE were determined in 211 patients with neuroendocrine tumors and compared to levels in a control group, consisting of 180 patients with nonendocrine neoplasms. The study and control groups showed comparable age distributions (53 \pm 14 and $54 \pm 13 \mathrm{yr}$, respectively). The sex distribution showed a higher male/female ratio for the study group (1.67 vs. 0.68), which can be ascribed to the high number of patients with breast carcinoma in the control group.
Because renal failure can increase circulating $\mathrm{CgA}$ concentrations (4), we evaluated whether this could cause falsely elevated levels. In the control group a significant relationship was demonstrated between a serum creatinine level higher than $133 \mu \mathrm{mol} / \mathrm{L}$ and increased levels of $\mathrm{CgA}(P<0.001$, by $\chi^{2}$ test). A creatinine concentration above $133 \mu \mathrm{mol} / \mathrm{L}$ was found in seven patients in the control group. Elevated serum concentrations of $\mathrm{CgA}$ (maximum, $371 \mu \mathrm{g} / \mathrm{L}$ ) were present in six of these patients. A creatinine level above $133 \mu \mathrm{mol} / \mathrm{L}$ was also present in three subjects in the study group (all with carcinoid tumor). One of these patients had normal and one had slightly increased CgA concentrations $(268 \mu \mathrm{g} / \mathrm{L})$. The third patient, with an extensively metastasized carcinoid tumor, had a creatinine level of $220 \mu \mathrm{mol} / \mathrm{L}$ and very high levels of CgA $(188,160 \mu \mathrm{g} / \mathrm{L})$. Although these extreme elevations probably cannot be attributed to the diminished renal function (4), these three study patients and seven control subjects with creatinine levels above $133 \mu \mathrm{mol} / \mathrm{L}$ were eliminated for further analysis of the data. Slightly elevated $\mathrm{CgA}$ concentrations can also occur in cases of severe liver dysfunction (4). This was not encountered in any of our study or control patients.

The results are summarized in Tables 1 and 2 and Fig. 1. The serum concentrations of $\mathrm{CgA}$ were elevated in 103 of 208 patients with neuroendocrine tumors. They were more frequently increased (in 50\% of the subjects) than the concentrations of NSE and $\alpha$-SU (in $43 \%$ and $24 \%$ of the subjects, respectively). The highest elevations of $\mathrm{CgA}$ were observed in subjects with carcinoid tumors (up to a maximum of 52,340 $\mu \mathrm{g} / \mathrm{L})$. Very high levels $(>1,000 \mu \mathrm{g} / \mathrm{L})$ were also seen in subjects with nonfunctioning pancreatic islet cell tumor, medullary thyroid carcinoma, pheochromocytoma, paraganglioma, small cell lung carcinoma, gastrinoma, and Merkel cell tumor. The levels were most frequently elevated in subjects with gastrinoma $(100 \%)$, pheochromocytoma $(89 \%)$, and carcinoid tumor $(80 \%)$. In subjects with pituitary adenoma $(13 \%)$, insulinoma $(10 \%)$, and paraganglioma $(8 \%)$, elevated CgA levels were only rarely present (Tables 1 and 2 and Fig. $1)$.

The highest levels of NSE were recorded in patients with small cell lung carcinoma and Merkel cell tumor (up to a maximum of $558 \mu \mathrm{g} / \mathrm{L}$ ). NSE was more frequently elevated than $\mathrm{CgA}$ in subjects with small cell lung carcinoma (in 74\% and $39 \%$, respectively), Merkel cell tumor (in 50\% and $25 \%$, respectively), insulinoma (in 38\% and 10\%, respectively), paraganglioma (in $36 \%$ and $8 \%$, respectively), and neuroblastoma (in $67 \%$ and $33 \%$, respectively).

The levels of $\alpha$-SU were most frequently elevated in patients with carcinoid tumors (39\%). Very high levels (up to a maximum of $353 \mu \mathrm{g} / \mathrm{L}$ ) were found in these patients. $\alpha$-SU concentrations higher than $10 \mu \mathrm{g} / \mathrm{L}$ were found in 7 of 59 subjects with carcinoid tumors $(12 \%)$, whereas they were never encountered in subjects with other neuroendocrine neoplasms.

Elevated levels of $\mathrm{CgA}, \alpha$-SU, and NSE were present in respectively $9(69 \%), 4(31 \%)$, and $3(23 \%)$ of 13 patients with nonfunctioning pancreatic islet cell tumors (Table 3). In 7 (54\%) of these 13 patients, CgA levels were markedly elevated $(>300 \mu \mathrm{g} / \mathrm{L})$.

Elevated levels of $\mathrm{CgA}, \alpha$-SU, and NSE were present in, 
TABLE 1. Serum levels of CgA, NSE, and $\alpha$-SU in patients with neuroendocrine tumors and in controls with nonendocrine tumors

\begin{tabular}{|c|c|c|c|c|c|c|c|}
\hline \multirow{2}{*}{ Type of tumor } & \multirow{2}{*}{$\begin{array}{l}\text { No. of } \\
\text { subjects }\end{array}$} & \multicolumn{2}{|c|}{$\mathrm{CgA}(\mu \mathrm{g} / \mathrm{L})$} & \multicolumn{2}{|c|}{$\operatorname{NSE}(\mu \mathrm{g} / \mathrm{L})$} & \multicolumn{2}{|c|}{$\alpha-\mathrm{SU}(\mu \mathrm{g} / \mathrm{L})$} \\
\hline & & Median & Range & Median & Range & Median & Range \\
\hline \multicolumn{8}{|l|}{ Neuroendocrine tumors $(\mathrm{n}=208)$} \\
\hline Carcinoid tumor & 59 & 688 & $33-52,340$ & 12 & $6-156$ & 1.5 & $0.6-353.0$ \\
\hline Medullary thyroid carcinoma & 26 & 184 & $80-13,900$ & 11 & $4-146$ & 1.1 & $0.6-3.7$ \\
\hline Paraganglioma & 25 & 106 & $50-11,590$ & 10 & $6-35$ & 0.9 & $0.6-2.0$ \\
\hline Pheochromocytoma & 9 & 275 & $110-4,674$ & 11 & $1-19$ & 0.9 & $0.6-1.8$ \\
\hline Neuroblastoma & 3 & 133 & $117-238$ & 36 & $12-100$ & 0.6 & $0.3-3.0$ \\
\hline Small cell lung carcinoma & 23 & 149 & $45-2,948$ & 27 & $6-511$ & 1.2 & $0.5-2.5$ \\
\hline Insulinoma & 21 & 105 & $63-236$ & 12 & $5-19$ & 1.1 & $0.5-3.4$ \\
\hline Gastrinoma & 9 & 772 & $289-1,933$ & 13 & $8-23$ & 1.6 & $0.5-4.7$ \\
\hline NF pancreatic islet cell tumor & 13 & 306 & $85-14,750$ & 10 & $5-91$ & 1.1 & $0.7-2.1$ \\
\hline Merkel cell tumor & 4 & 109 & $84-1,056$ & 23 & $7-558$ & 1.0 & $0.6-2.5$ \\
\hline Clinically NF pituitary adenoma & 10 & 131 & $85-240$ & 10 & $8-12$ & 0.9 & $0.6-3.6$ \\
\hline GH-secreting pituitary adenoma & 6 & 71 & $53-115$ & 8 & $6-10$ & 0.9 & $0.5-1.7$ \\
\hline \multicolumn{8}{|l|}{ Nonendocrine tumors $(n=173)$} \\
\hline Breast carcinoma & 62 & 96 & $55-8,307$ & 11 & $4-26$ & 1.5 & $0.4-13.0$ \\
\hline Nonsmall cell lung cancer & 23 & 95 & $47-219$ & 11 & $5-41$ & 1.1 & $0.6-6.7$ \\
\hline Pancreatic adenocarcinoma & 20 & 116 & 51-395 & 11 & $6-24$ & 1.1 & $0.5-2.9$ \\
\hline Adenocarcinoma uo & 12 & 119 & $68-154$ & 12 & $7-44$ & 1.3 & $0.7-2.7$ \\
\hline Non-Hodgkin lymphoma & 24 & 99 & $67-185$ & 10 & $5-22$ & 1.1 & $0.5-2.3$ \\
\hline Hodgkin lymphoma & 13 & 75 & $22-161$ & 10 & $6-52$ & 1.0 & $0.7-1.4$ \\
\hline Multiple myeloma & 5 & 162 & $98-215$ & 13 & $9-15$ & 1.1 & $0.8-1.7$ \\
\hline Meningioma & 10 & 89 & $57-134$ & 11 & $6-32$ & 1.0 & $0.4-2.6$ \\
\hline Astrocytoma & 4 & 86 & $66-121$ & 6 & $5-52$ & 0.8 & $0.6-0.8$ \\
\hline
\end{tabular}

NF, Nonfunctioning; uo, unknown origin.

TABLE 2. Presence of elevated serum levels of CgA, NSE, and $\alpha$-SU in patients with neuroendocrine tumors and controls with nonendocrine tumors

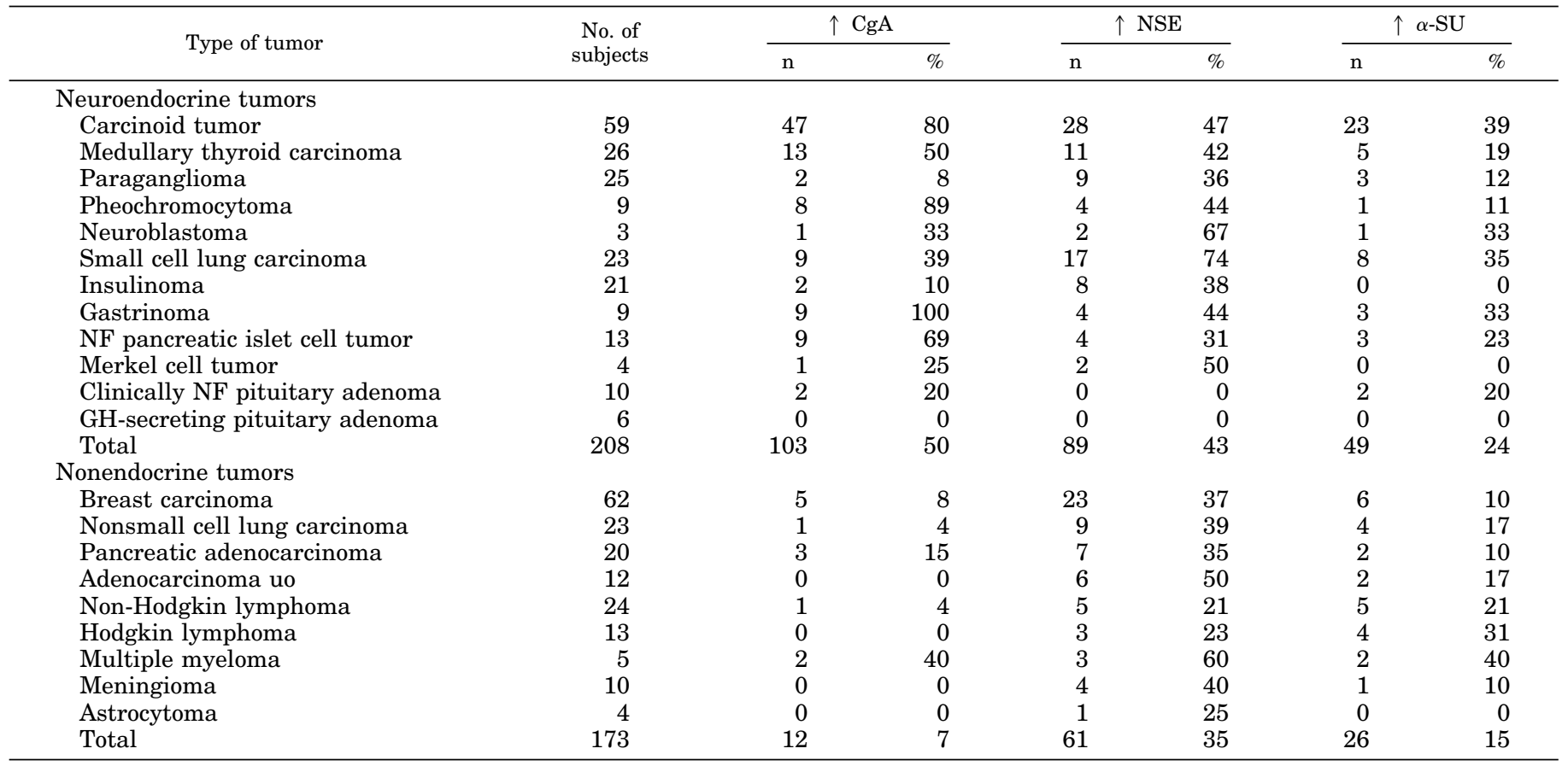

$\mathrm{n}$, Number of subjects with elevated levels.

respectively, $7 \%, 15 \%$, and $35 \%$ of control subjects with nonendocrine neoplasms.

When these control subjects were used as reference population, the sensitivities of $\mathrm{CgA}, \mathrm{NSE}$, and $\alpha$-SU for the diagnosis of peripheral neuroendocrine tumors (pituitary adenomas excluded) were, respectively, 53\%, 46\%, and $26 \%$, with specificities of $93 \%, 65 \%$, and $85 \%$. We applied, how- ever, a rather high upper cut-off value for CgA, corresponding to slightly more than $3 \mathrm{SD}$ above the mean, to avoid overlapping values with normal subjects. Usually 2 SD above the mean is used as the upper cut-off level, increasing the risk of overlap. When we reanalyzed our data using 2 SD as the upper cut-off level, the sensitivity hardly improved to $58 \%$ with a specificity of $90 \%$. When using $300 \mu \mathrm{g} / \mathrm{L}$ as the upper 
FIG. 1. Serum concentrations of CgA in patients with neuroendocrine tumors and in controls with nonendocrine tumors. Individual levels are presented as dots; median levels as lines. The dashed line represents the upper cut-off level of $220 \mu \mathrm{g} / \mathrm{L}$. The results are plotted logarithmically to accommodate extreme values. MTC, Medullary thyroid carcinoma; Pheo, Pheochromocytoma; SCLC, Small cell lung carcinoma; GH, GH-producing; NF, Nonfunctioning.

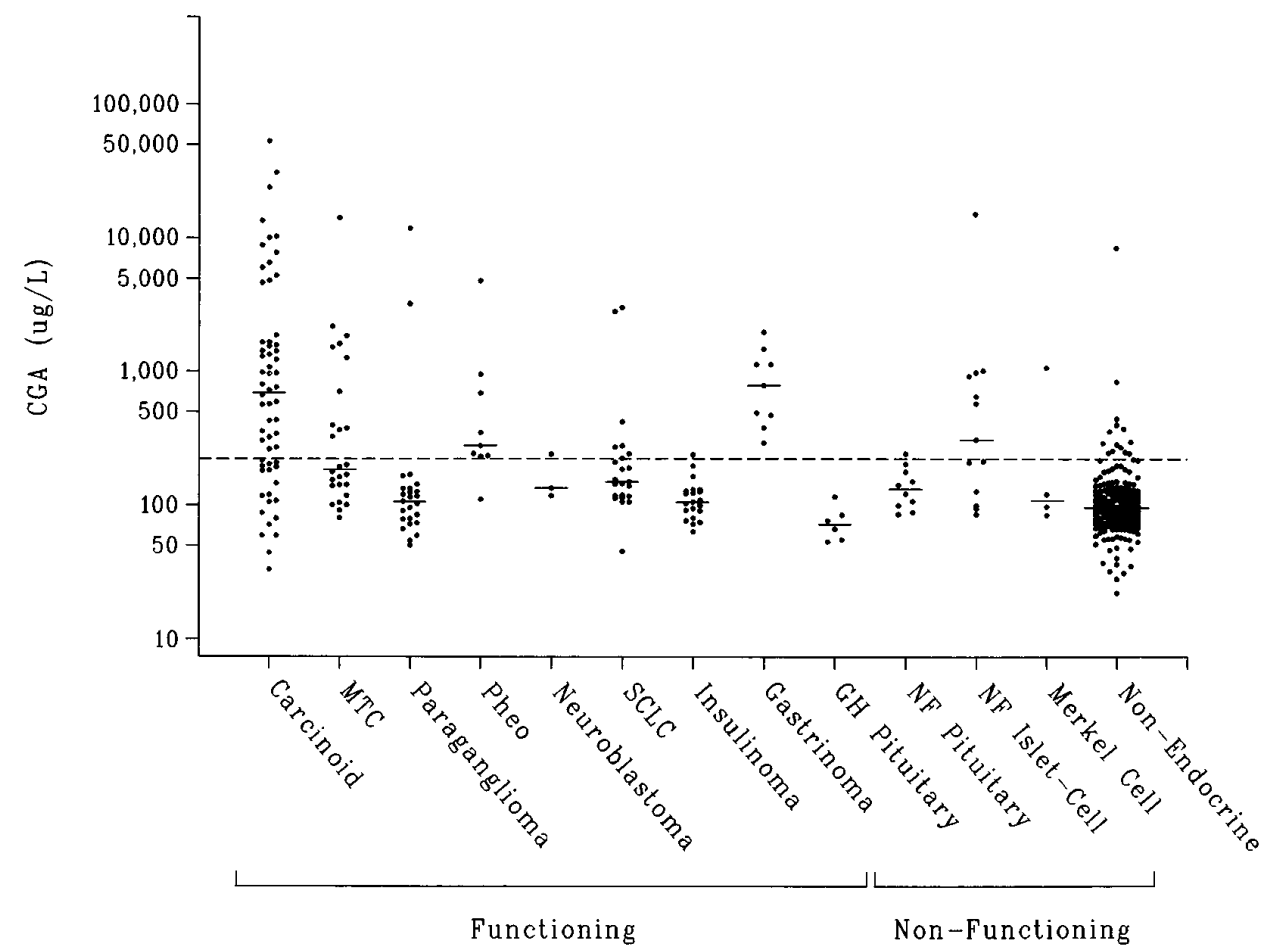

(Table 4). A weak, but significant, relationship was present between the presence and absence of elevated serum concentrations of $\mathrm{CgA}$ and $\alpha$-SU $\left(P=0.05\right.$, by $\chi^{2}$ test $)$ in subjects with carcinoid tumors, who frequently had elevated $\alpha$-SU levels. In patients with small cell lung carcinoma, who frequently had elevated NSE levels, no significant relationship could be shown between CgA and NSE concentrations.

\section{Relationship with other neuroendocrine markers}

Measurements of 24-h urinary 5-hydroxyindole acetic acid (5-HIAA) excretions were available in 46 of 59 patients with carcinoid tumors. Increased levels $(>40 \mu \mathrm{mol} / 24 \mathrm{~h})$ were present in 31 patients $(67 \%)$. Elevated serum concentrations of CgA were demonstrated in 30 of these 31 subjects $(97 \%$; $P<0.01$, by $\chi^{2}$ test). A significant correlation was also present between the absolute values of serum CgA and 24-h urinary 5-HIAA excretion (Spearman rank correlation test; $\mathrm{r}=0.65$; $P<0.01$ ). No significant relationships were demonstrated between $\alpha$-SU and NSE concentrations, on the one hand, and urinary 5-HIAA excretions, on the other hand $(P>0.05$, by $\chi^{2}$ tests).

Determinations of serum calcitonin and carcinoembryonic antigen (CEA) concentrations were available in, respectively, 20 and 21 of 26 subjects with medullary thyroid carcinoma. Calcitonin was elevated $(>0.14 \mu \mathrm{g} / \mathrm{L})$ in 18 of 20 patients $(90 \%)$, and CEA $(>10 \mu \mathrm{g} / \mathrm{L})$ was elevated in 18 of 21 patients $(86 \%)$. Elevated CEA levels were present in the 2 patients with normal calcitonin levels. In 1 of these 2 subjects, slightly elevated concentrations of CgA $(192 \mu \mathrm{g} / \mathrm{L})$ and $\alpha$-SU $(1.5$ $\mu \mathrm{g} / \mathrm{L})$ were found. $\mathrm{CgA}, \alpha-\mathrm{SU}$, and NSE levels were not increased in the 3 patients with normal CEA levels. Significant correlations were demonstrated between serum $\mathrm{CgA}$, on the one hand, and calcitonin (by Spearman rank correlation test: $\mathrm{r}=0.79 ; P<0.01)$ and $\mathrm{CEA}(\mathrm{r}=0.84 ; P<0.01)$, 
TABLE 4. Relations between serum levels of CgA, NSE, and $\alpha$-SU in subjects with neuroendocrine tumors

\begin{tabular}{|c|c|c|c|c|c|c|c|c|c|c|c|}
\hline \multirow{2}{*}{$\begin{array}{l}\chi^{2}=18.10 \\
(P<0.001)\end{array}$} & \multicolumn{2}{|c|}{$\mathrm{CgA}$} & \multirow{2}{*}{$\begin{array}{l}\text { No. of } \\
\text { subjects }\end{array}$} & \multirow{2}{*}{$\begin{array}{l}\chi^{2}=1.08 \\
(P=\text { NS })\end{array}$} & \multicolumn{2}{|c|}{$\mathrm{CgA}$} & \multirow{2}{*}{$\begin{array}{l}\text { No. of } \\
\text { subjects }\end{array}$} & \multirow{2}{*}{$\begin{array}{l}\chi^{2}=0.05 \\
(P=\mathrm{NS})\end{array}$} & \multicolumn{2}{|c|}{ NSE } & \multirow{2}{*}{$\begin{array}{c}\text { No. of } \\
\text { subjects }\end{array}$} \\
\hline & Normal & $\overline{\text { Elevated }}$ & & & Normal & Elevated & & & Normal & Elevated & \\
\hline$\alpha-\mathrm{SU}$ & & & & NSE & & & & $\alpha-\mathrm{SU}$ & & & \\
\hline Normal & 93 & 66 & 159 & Normal & 64 & 56 & 120 & Normal & 92 & 67 & 159 \\
\hline Elevated & 12 & 38 & 50 & Elevated & 41 & 48 & 89 & Elevated & 28 & 22 & 50 \\
\hline No. of subjects & 105 & 104 & 209 & & 105 & 104 & 209 & & 120 & 89 & 209 \\
\hline
\end{tabular}

NS, $P>0.05$.

on the other hand, as well as between NSE, on the one hand, and calcitonin $(\mathrm{r}=0.71 ; P<0.01)$ and CEA $(\mathrm{r}=0.82 ; P<$ $0.01)$, on the other hand. $\alpha$-SU showed a correlation with calcitonin $(\mathrm{r}=0.63 ; P<0.01)$, but no significant correlation with CEA ( $\mathrm{r}=0.33 ; P>0.05)$.

Determinations of 24-h urinary excretions of vanilmandelic acid (VMA) were only available in five of nine patients with pheochromocytoma. The highest levels of CgA were found in the patients with the highest urinary VMA excretion, although the small number of cases did not permit statistical evaluation.

\section{Relationship with tumor load}

Using computed tomography scan images and octreotide scintigrams, information on tumor volume could be obtained in subjects with the following neuroendocrine neoplasms: 60 carcinoid tumors, 26 medullary thyroid carcinomas, 25 paragangliomas, 11 small cell lung carcinomas, 9 gastrinomas, and 12 nonfunctioning pancreatic islet cell tumors. Tumor load was considered to be limited when 1 or 2 localizations were found and was considered extensive when more than 3 localizations were demonstrated. A highly significant positive relationship was demonstrated between the tumor load and serum CgA levels ( $P<0.01$, by $\chi^{2}$ test). Such a relationship could not be shown for $\alpha$-SU or NSE. In the individual neuroendocrine neoplasms, the relationship between tumor load and CgA levels was only significant in subjects with carcinoid tumors. Because they represent the largest subgroup, statistical significance is more easily reached. Gastrinomas form an exception to the rule that small neuroendocrine tumors have low $\mathrm{CgA}$ levels; elevated $\mathrm{CgA}$ levels were detected in all patients with gastrinomas, although they all presented with limited neoplastic disease.

\section{Discussion}

We evaluated the clinical usefulness of CgA, NSE, and $\alpha$-SU as serum markers of neuroendocrine neoplasia in general. Serum concentrations were measured in a large group of patients with several neuroendocrine tumors and compared with those in a large control group with a variety of nonendocrine tumors.

The highest concentrations of $\mathrm{CgA}$, with values up to 250 times the upper limit of normal, were observed in subjects with carcinoid tumors, medullary thyroid carcinomas, pheochromocytomas, and some tumors of the endocrine pancreas. This confirms the results of previous smaller studies $(2$, $4,5)$. Elevated levels were also frequently encountered in subjects with peripheral (nonpituitary) neuroendocrine tumors without detectable hormonal secretion. These so-called chromograninomas were first described by Sobol and coworkers (3). Serum concentrations of $\mathrm{CgA}$ are only rarely increased, however, in cases of clinically nonfunctioning pituitary adenomas. This is probably due to the small volume of these adenomas (6).

We demonstrated a significant positive relation between the serum levels of $\mathrm{CgA}$ and the tumor mass of the neuroendocrine neoplasms. This confirms our earlier findings in Cushing's syndrome caused by ectopic ACTH production by extrapituitary neuroendocrine tumors (8) and the findings by O'Connor and Deftos (2) and Hsiao and co-workers (9) in pheochromocytomas. The serum concentrations of $\mathrm{CgA}$ are only rarely slightly elevated in subjects with small neuroendocrine tumors, such as insulinomas, paragangliomas, or pituitary adenomas $(6,8,10)$. These tumors are usually detected at an early stage of oncological evolution, because they rapidly induce symptoms due to active hormonal secretion or compression of important surrounding tissues. The presence of $\mathrm{CgA}$ or its messenger ribonucleic acid can nearly always be demonstrated in the cells of these tumors by immunohistochemistry or in situ hybridization $(6,11,12)$. Nevertheless, it must be assumed that the small amount of $\mathrm{CgA}$ released by these neoplasms usually fails to elevate the serum concentration above the physiological background level. Increased CgA concentrations were detected, however, in all of our patients with gastrinoma, although they all had a very limited tumor burden. It is well known that chronic elevation of gastrin levels provokes hyperplasia of the neuroendocrine cells of the stomach (13). As these cells are able to secrete $\mathrm{CgA}$, they might be responsible for the elevated $\mathrm{CgA}$ concentrations. Stabile and co-workers demonstrated that the $\mathrm{CgA}$ concentrations can be normalized by gastrectomy alone, without resection of the gastrin-producing tumor (and thus without correction of the elevated gastrin levels) (14).

In our hands, CgA had a smaller sensitivity for the detection of neuroendocrine neoplasms than reported in previous studies $(2,4,5)$. However, the technical characteristics of our RIA for CgA are very similar to those of the other assays used in frequently cited publications $(4,15)$. A small neuroendocrine tumor mass was present in a rather large percentage of our patients, in contrast to the hitherto published series, in which almost all tumors were extensively metastasized $(2,4,5)$. This can probably be explained by the fact that patients tend to be transferred earlier in their oncological evolution, after the development of $\left[{ }^{111}\right.$ In-DTPAD-Phe ${ }^{1}$ loctreotide scanning for the visualization of neuroendocrine tumors in our hospital. Many patients with biochemical proof of a neuroendocrine tumor were trans- 
ferred for somatostatin receptor scintigraphy after conventional radiography failed to elucidate the location of the tumor. The inclusion of a number of patients with these smaller tumors decreased the overall sensitivity of serum $\mathrm{CgA}$ in our series.

The specificity of elevated levels of $\mathrm{CgA}$ in the diagnosis of neuroendocrine tumors was also lower in our study than in previous ones $(2,4,5)$. O'Connor and co-workers $(2,4)$ and Erikkson and co-workers (5) reported specificities of $100 \%$. By contrast, we used a much larger control group, consisting of patients with a greater variety of nonendocrine tumors. After excluding patients with decreased renal function, elevated serum concentrations of $\mathrm{CgA}$ were demonstrated in 12 of 173 nonendocrine neoplasms (7\%). The serum levels in these control patients were usually only slightly elevated. They exceeded $300 \mu \mathrm{g} / \mathrm{L}$ in only 3 of 173 patients (2\%) compared to 76 of 208 patients (37\%) with neuroendocrine tumors. Thus, finding an excessively elevated level of $\mathrm{CgA}$ firmly suggests the presence of a neuroendocrine tumor.

It is well established that many nonendocrine tissues contain neuroendocrine cells, belonging to the amino-precursoruptake-decarboxylation system. A substantial body of data has accumulated in the literature during recent years, revealing that these cells are also present in most tumors of nonendocrine origin (16-20). They are either diffusely scattered throughout the tumor or multifocally located in small nests. In malignant tumors these neuroendocrine cells even participate in the neoplastic growth, as they show nuclear abberations and are present in locally invasive or metastatic tumor tissue. The number of tumors harboring these neuroendocrine cells or the percentage of neuroendocrine cells in a tumor depend on the tumor type, the number of neuroendocrine markers used, and the detection technique (histochemistry for argyrophilia, immunohistochemistry, or detection of messenger ribonucleic acid of neuroendocrine markers). These cells probably secrete $\mathrm{CgA}$, as it is present in their dense core secretory granules. There are only scarce data available in the literature concerning serum levels of $\mathrm{CgA}$ in subjects with nonendocrine tumors. Elevated levels were reported in patients with carcinomas of the prostate gland $(21,22)$ and in cases of nonsmall cell lung cancer (23). Whether proliferation of neuroendocrine cells also occurs in hematological neoplasms is not known. One study reported the presence of scarcely distributed CgA-positive cells in the normal spleen, lymph nodes, and thymus (24).

As a general neuroendocrine marker, $\mathrm{CgA}$ cannot differentiate between different subtypes of neuroendocrine neoplasms. Most tumors of neuroendocrine origin release typical secretion products that can be used as specific serum markers. These markers usually provide a higher sensitivity and specificity than $\mathrm{CgA}$, as illustrated by our data comparing calcitonin and CEA with CgA in subjects with medullary thyroid carcinoma. In these situations the usefulness of $\mathrm{CgA}$ is limited, because it does not provide additional information. By contrast, $\mathrm{CgA}$ can have interesting clinical applications in so-called nonfunctioning neuroendocrine tumors that are either not able to secrete hormonal products or release products that cannot be detected by current techniques. It can also be useful in neuroendocrine tumors in which other diagnostic procedures have their limitations (e.g. fluctuating levels of serum catecholamines in pheochromocytoma) or are inconvenient (e.g. 24-h urine collections for 5-HIAA determination in carcinoid tumors). Our data illustrate the value of $\mathrm{CgA}$ in these conditions: increased levels were found in $69 \%$ of nonpituitary, hormone-negative neuroendocrine tumors, $89 \%$ of pheochromocytomas, and $80 \%$ of carcinoid tumors. Very high concentrations were frequently encountered in these patients.

NSE is the neuron-specific isomer of the glycolytic enzyme 2-phospho-D-glycerate hydrolase or enolase (25). It is a widely used immunohistochemical and serum marker for neuroendocrine tissues and is especially known as a marker for small cell lung carcinoma (26). Our data confirm the frequent elevation of its serum concentrations in patients with several neuroendocrine tumors (27-29). The highest levels were encountered in small cell lung carcinoma and in the rare cases of Merkel cell tumors. Serum concentrations of NSE are more often elevated than those of $\mathrm{CgA}$ in subjects with these tumors and in those with insulinomas, paragangliomas, and neuroblastomas. The specificity of serum NSE for the diagnosis of neuroendocrine tumors is, however, much lower than that of serum CgA. Increased NSE levels were demonstrated in 61 of 173 subjects with nonneuroendocrine neoplasms (35\%) compared to 89 of 192 with peripheral (nonpituitary) neuroendocrine tumors $(46 \%)$. Unlike CgA, the specificity of NSE can hardly be improved by increasing the upper cut-off value. Therefore, NSE cannot be considered a good diagnostic marker for neuroendocrine tumors, but can be very useful as a follow-up marker, especially for small cell lung carcinoma and Merkel cell tumors.

The $\alpha$-SU of the glycoprotein hormones is a well known marker of pituitary adenomas of gonadotroph origin (6). Recent studies suggest that determination of the serum concentrations of $\alpha$-SU might also be of value in patients with peripheral neuroendocrine neoplasms (30-32). Our data confirm the presence of elevated serum levels in several subjects with these neoplasms. Again, as with CgA and NSE, the marker lacks specificity. Serum levels were elevated in 26 of 173 subjects with nonneuroendocrine neoplasms (15\%) compared to 47 of 192 with peripheral neuroendocrine tumors (24\%). Increasing the cut-off level again failed to improve the specificity. Very high levels were frequently detected in patients with carcinoid tumors; 7 of 59 subjects with carcinoid tumors $(12 \%)$ had levels higher than $10 \mu \mathrm{g} / \mathrm{L}$. Such high levels were only encountered once in the control group, in a patient with breast carcinoma. Thus, the finding of very high serum concentrations of $\alpha$-SU suggests the presence of a carcinoid tumor when tumors of germ cell or trophoblastic origin are excluded. The clinical usefulness of $\alpha$-SU as a marker for neuroendocrine tumors is limited, however, because most subjects with elevated levels also have elevated $\mathrm{CgA}$ concentrations.

In conclusion, $\mathrm{CgA}$ is the best general neuroendocrine serum marker available. It had the highest specificity for the detection of neuroendocrine tumors of the three tested markers. Unfortunately, it is not a very sensitive marker; its serum concentrations seem to rise relatively late in the evolution of the tumor. Although its specificity cannot compete with that of the specific hormonal secretion products of most neuroendocrine tumors, it can have useful clinical applications 
in subjects with neuroendocrine tumors for which either no marker is available (so-called nonfunctioning neuroendocrine tumors) or the marker is inconvenient for daily clinical use (e.g. 24-h urinary 5-HIAA excretions and plasma catecholamines).

\section{References}

1. Deftos LJ. 1991 Chromogranin A: its role in endocrine function, and as an endocrine and neuroendocrine tumor marker. Endocr Rev. 12:181-187.

2. O'Connor DT, Deftos LJ. 1986 Secretion of chromogranin A by peptideproducing endocrine neoplasms. N Engl J Med. 314:1145-1151.

3. Sobol RE, Memoli V, Deftos LJ. 1989 Hormone-negative, chromogranin Apositive endocrine tumors. N Engl J Med. 320:444-447.

4. O'Connor DT, Pandian MR, Carlton E, Cervenka JH, Hsiao RJ. 1989 Rapid radioimmunoassay of circulating chromogranin A: in vitro stability, exploration of the neuroendocrine character of neoplasia, and assessment of the effects of organ failure. Clin Chem. 35:1631-1637.

5. Eriksson B, Arnberg H, Öberg K, et al. 1990 A polyclonal antiserum against chromogranin A and B-a new sensitive marker for neuroendocrine tumors. Acta Endocrinol (Copenh). 122:145-155.

6. Nobels FRE, Kwekkeboom DJ, Coopmans W, Hoekstra R, Bouillon R, Lamberts SWJ. 1993 A comparison between the diagnostic value of the measurement of gonadotropins, $\alpha$-subunits and chromogranin $\mathrm{A}$ and their response to TRH in clinically nonfunctioning, $\alpha$-subunit secreting and gonadotroph pituitary adenomas. J Clin Endocrinol Metab. 77:784-789.

7. Lamberts SWJ, Bakker WH, Reubi J-C, Krenning EP. 1990 Somatostatinreceptor imaging in the localization of endocrine tumors. N Engl J Med. 323:1246-1249.

8. Nobels FRE, de Herder WW, Kwekkeboom DJ, et al. 1994 Serum chromogranin $\mathrm{A}$ in the differential diagnosis of Cushing's syndrome. Eur J Endocrinol 131:589-593.

9. Hsiao RJ, Neumann HPH, Parmer RJ, Barbosa JA, O'Connor DT. 1990 Chromogranin A in familial pheochromocytoma: diagnostic screening value, prediction of tumor mass, and post-resection kinetics indicating two-compartment distribution. Am J Med. 88:607-613.

10. Deftos LJ, O'Connor DT, Wilson CB, Fitzgerald PA. 1989 Human pituitary tumors secrete chromogranin-A. J Clin Endocrinol Metab 68:869-872.

11. Weiler R, Fischer-Colbrie R, Schmid KW, et al. 1988 Immunological studies on the occurrence and properties of chromogranin A and B and secretogranin II in endocrine tumors. Am J Surg Pathol. 12:877-884.

12. Lloyd RV, Iacangelo A, Eiden LE, Cano M, Jin L, Grimes M. 1989 Chromogranin A, and B messenger ribonucleic acids in pituitary and other normal and neoplastic human endocrine tissues. Lab Invest. 60:548-556.

13. D'Adda T, Corleto V, Pilato FP, et al. 1990 Quantitative ultrastructure of endocrine cells of oxyntic mucosa in Zollinger-Ellison syndrome. Gastroenterology. 99:17-26.

14. Stabile BE, Howard TJ, Passaro E, O'Connor DT. 1990 Source of plasma chromogranin A elevation in gastrinoma patients. Arch Surg. 125:451-453.

15. O'Connor DT, Bernstein KN. 1984 Radioimmunoassay of chromogranin A in plasma as a measure of exocytotic sympathoadrenal activity in normal subjects and patients with pheochromocytoma. N Engl J Med. 311:764-770.

16. Sundaresan V, Reeve JG, Stenning S, Stewart S, Bleehen NM. 1991 Neuroendocrine differentiation and clinical behaviour in non-small cell lung tumors. Br J Cancer. 64:333-338.

17. Scopsi L, Andreola S, Pilotti S, et al. 1992 Argyrophylia and granin (chromogranin/secretogranin) expression in female breast carcinomas. Their relationship to survival and other disease parameters. Am J Surg Pathol. 16:561-576

18. di Sant'Agnese PA. 1992 Neuroendocrine differentiation in carcinoma of the prostate. Diagnostic, prognostic and therapeutic implications. Cancer. 70:254-268

19. De Bruïne AP, Wiggers T, Beek C, et al. 1993 Endocrine cells in colorecta adenocarcinomas: incidence, hormone profile and prognostic relevance. Int J Cancer. 54:765-771

20. Pour PM, Permert J, Mogaki M, Fujii H, Kazakoff K. 1993 Endocrine aspects of exocrine cancer of the pancreas. Their patterns and suggested biologic significance. Am J Clin Pathol. 100:223-230.

21. Kadmon D, Thompson TC, Lynch GR, Scardino PT. 1991 Elevated plasma chromogranin-A concentrations in prostatic carcinoma. J Urol. 146:358-361.

22. Deftos LJ, Nakada S, Burton DW, di Sant'Agnese PA, Cockett AT, Abrahamsson PA. Immunoassay and immunohistology studies of chromogranin A as a neuroendocrine marker in patients with carcinoma of the prostate. Urology 96;48:58-62.

23. Sobol RE, O'Connor DT, Addison J, Suchocki K, Royston I, Deftos LJ. 1986 Elevated serum chromogranin A concentrations in small-cell lung carcinoma. Ann Intern Med. 105:698-700.

24. Hogue-Angeletti R, Hickey WF. 1985 A neuroendocrine marker in tissues of the immune system. Science. 230:89-90.

25. Schmechel D, Marangos PJ, Brightman M. 1978 Neuron-specific enolase is a molecular marker for peripheral, and central neuroendocrine cells. Nature. 276:834-836.

26. Akoun GM, Scarna HM, Milleron BJ, Bénichou MP, Herman DP. 1985 Serum neuron-specific enolase. A marker for disease extent and response to therapy for small-cell lung cancer. Chest. 87:39-43.

27. Oishi S, Sato T. 1988 Elevated serum neuron-specific enolase in patients with malignant pheochromocytoma. Cancer. 61:1167-1170.

28. Cunningham RT, Johnston CF, Irvine GB, Buchanan KD. 1992 Serum neurone-specific enolase levels in patients with neuroendocrine and carcinoid tumors. Clin Chim Acta. 212:123-131.

29. D'Alessandro M, Mariani P, Lomanto D, Carlei F, Lezoche E, Speranza V. 1992 Serum neuron-specific enolase in diagnosis and follow-up of gastrointestinal neuroendocrine tumors. Tumor Biol. 13:352-357.

30. Heitz PU, von Herbay G, Klöppel G, et al. 1987 The expression of subunits of human chorionic gonadotropin (hCG) by nontrophoblastic, non-endocrine and endocrine tumors. Am J Clin Pathol. 88:467-472.

31. Eriksson B, Oberg K, Skogseid B. 1989 Neuroendocrine pancreatic tumors Clinical findings in a prospective study of 84 patients. Acta Oncol. 28:373-377.

32. Grossmann M, Trautmann ME, Poertl S, et al. 1994 Alpha-subunit and human chorionic gonadotropin-beta immunoreactivity in patients with malignant endocrine gastroenteropancreatic tumors. Eur J Clin Invest. 24:131-136. 